\title{
The Formula of Dependence of Mechanical Characteristics of Materials on Crystalline Phase Composition in the Matrix
}

\author{
Z. Kovziridze \\ Institute of Bionanoceramics and Nanocomposite Technology, Georgian Technical University, Tbilisi, Georgia \\ Email: kowsiri@gtu.ge
}

How to cite this paper: Kovziridze, $\mathrm{Z}$. (2020) The Formula of Dependence of Mechanical Characteristics of Materials on Crystalline Phase Composition in the Matrix. Advances in Materials Physics and Chemistry, 10, 178-188.

https://doi.org/10.4236/ampc.2020.108013

Received: June 12, 2020

Accepted: August 18, 2020

Published: August 21, 2020

Copyright $\odot 2020$ by author(s) and Scientific Research Publishing Inc. This work is licensed under the Creative Commons Attribution International License (CC BY 4.0).

http://creativecommons.org/licenses/by/4.0/

\begin{abstract}
Objective: For materials science and generally, for long-term operation of work-pieces in industry the significant role is attributed to dependence of macro-mechanical properties of consolidated body on crystalline phase composition, its dimensions, form, distribution in matrix and the form factor. While working in responsible fields of technology of ceramics and ceramic composites the above referred properties are attributed extremely great role with the view of durability and endurance at the terms of heavy mechanical loads. For description of the resistance of any concrete type work-piece, the crystalline phase plays the greatest role in mechanical strength or deformation of any material. It plays the important role in correlative explanation of materials mechanics and matrix properties. In our case, in the process of destruction of ceramic materials and composites, which will give us exhaustive response to the role of macro- and micro-mechanical properties of materials, the role of a macro- and micro-structural component, that is, of crystalline phase in the process of transition of stable state of materials into meta-stable state is extremely big. Our study aims to develop a formula of dependence of macro-mechanical properties of ceramic and ceramic composites on crystalline phase, the most powerful component of their structure, which will enable theorists and practitioners to select and develop technologies and technological processes correctly. Method: On the basis of the study of micro- and macro-mechanical properties of ceramics and ceramic composites and the morphology of crystalline phase and the analysis of the study we determined and created parameters of the formula. Results: The formula covers macro-mechanical properties, that is when the work-piece is thoroughly destructed: mechanic at bending at three and four-point load, mechanic at contraction; among morphological characteristics: composition of crystalline phase and their spreading in matrix, their sizes, form factor; correlative dependence
\end{abstract}


of the above listed properties. Absolutely new definition of a factor of spreading of crystalline phase in matrix is offered. Conclusion: The created formula is of consolidated nature and it can be used in technology of any ceramic material and ceramic composites. The formula will help practitioners to plan correctly and fulfill accurately all positions of technology of production of work-pieces, to carry out the most responsible thermal treatment process of technology of manufacture of work-pieces; to determine correlation between mechanical and matrix properties of materials.

\section{Keywords}

Crystalline Phase, Macro-Mechanical Properties, Mechanic at Bending, Mechanic at Compaction, Factor of Spreading of Crystalline Phase in Matrix

\section{Introduction}

Decomposition of crystals takes place in two stages: the first stage is formation of a crack, the second is its growth before the sample is completely decomposed. The speed of this process as a whole can be controlled by the speed of the flow of any stage. The process of decomposition is rather complicated. The influence of those basic factors participating in the decomposition process is extremely important. It is observed that fragile isotropic materials are decomposed when a critical stretching tension is achieved in any direction, as well as critical stress strains are an unavoidable feature for plastic deformations. In a number of cases decomposition is not connected with a crystallographic factor and the crack in the sample develops randomly. If an isotropic solid body extends, stretches under mechanical loadings, then the distance between the atoms will be increased. For this reason, we need to put such a load on the sample that will be equal to the dependence of the interatomic binding on the existing distances and the extension of the sample will be consistent with the certain energy required to achieve the elastic deformation of the sample and which must be expended during the decomposition process to increase the surface energy of the system to produce new surfaces in it.

If the specific surface energy is equal to $y$, then the energy expended by splitting the fractions on the surfaces of the sample, which is equal to one, will be equal to $2 y$.

A significant proportion of the energy required at the time of decomposition must be accumulated between atoms (or between molecules) that are close directly to the decomposition surface. So, if $\sigma_{a v}$ is the average strain at which the decomposition begins, then $\sigma_{a v}^{2} / 2 E$ is the density of the elastic deformation or the hook law is maintained and the value of the elastic modulus is also normal. $\sigma_{a v}^{2} / 2 E E$ energy on two planes of atoms spaced from each other at a distance of " $a$ " should be equal in magnitude to the surface energy $y$. Accordingly we can find the magnitude of the decomposing stress from the Equation (1) [1] 


$$
\sigma_{a v .} \approx \sqrt{\frac{2 y E}{a}} \approx \frac{E}{10}
$$

For crystalline substances the magnitude of the elastic modulus of which is at the interval of (1 - 5) $105 \mathrm{MPa}$, the theoretical strength is approximately (1 - 5) $104 \mathrm{MPa}$.Stretch strains of this magnitude can withstand a variety of crystal material (Brenner, 1958). Such difference between practical and theoretical data was first explained by Griffith A.A [2] [3]. According to the theory of GriffithOrowan the difference between the theoretical and real strength in solid materials is a result of the narrowest invisible cracks existed in them, with which there is a strong concentration of tension. So, the stress at which the disintegration occurs is equal to the theoretical strength, although it occurs in some small areas of the sample while the average magnitude of the stress on the sample is not yet large.In calculating the stress concentrations at the edge of the crack, Griffith used the theory developed by Inglis C.E. [4] for the case of the distribution of stress around a very thin elliptical-shaped cavity.If there is a normal stretching stress $\sigma_{a v}$. in the direction of the $2 c$ main axis of the crack, then the greatest tensile stress at the end of the crackwill be:

$$
\sigma_{\max }=\sigma_{a v \cdot \sqrt{\frac{c}{\rho}}}
$$

where $\rho$ is a curvature radius of the crack edge.

The formula shows that if $\rho$ tends to zero, then the maximum stress tends to infinity even if the average stresslevel is too small.A surface crack on a crystal at a depth of $c$ will create approximately the same concentration of stresses as an internal crack with a magnitude of $2 c$. Accordingly, Griffith's results are acceptable as for surface cracks, as well as for cracks inside the sample. Orowan later [5] argued that due to physical condition, the radius of curvature could not be equal to zero. At the edge of the crack it should be approximately equal to the distances " $a$ " between atoms. If we put the magnitude of " $a$ " instead of $2 \rho$ and equate the resulting image of the right side of the equation to 1 , we get the average magnitude of the direct strain, during which the microscopic tensions at the edge of the crack, with the curvature about the distances between the atoms, reach the theoretical tension.

$$
\sigma_{s t .}=\sqrt{\frac{y E}{2 c}}
$$

According to this theory decomposition of solid materials in which there are cracks and which are acting as concentrators of tension, will take place in the conditionls of those tensions, which are really observed. These cracks must have the length of $1 \mathrm{mkm}$ and the curvature at the crack edge must be about the value of distances between the atoms. According to Charles [6], the fact that the process leads to relatively fast solubility of the substance at the edge of the crack compared to its solubility (which is necessary for gradual increase in crack and increase in stress concentration) is due to the increase in stretching tension at the edge of 
the crack which leads the process to the relatively strong expansion of the crystal lattice at its edges.At the expense of this, the rate of corrosion increases in this area of the lattice.

\section{Basic Part}

\section{Static Fatigue}

In addition to the fragile decomposition characteristic of crystalline ceramics, their strength also depends on the the load time or the speed at which the applied load is increasing, i.e the load velocity (Picture 1) [7].

Most ceramic materials have a glassy phase that contains oxidized elements of alkaline elements, and there are rare cases where decomposition occurs slowly. At this time, the dependence of the load on the speed is frequent (Table 1).

Slowly decomposing or static fatigue should generally be considered as a general occurrence with respect to crystalline materials that do not contain a glassy phase.

\section{Influence of microstructure}

For most ceramic materials, the role of the microstructure will be mainly influenced by the porous phase. Existing pores reduce the cross-sectional area of the material on which the load is applied and act as tension concentrators. In isolated spherical pores the tension increases twice. Experiments show that the

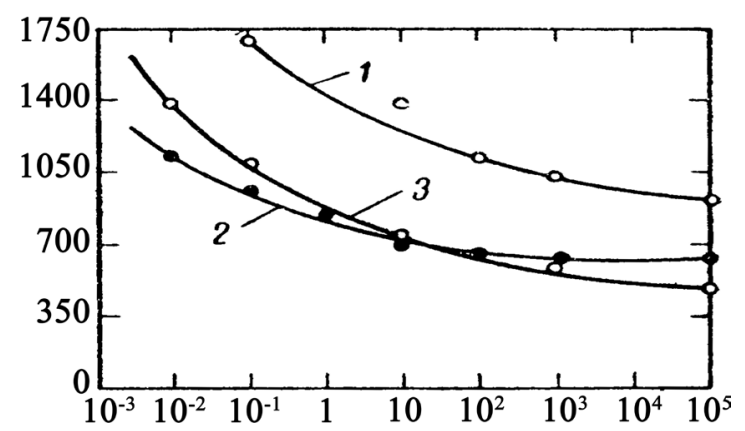

Picture 1. Dependence of the magnitude of the tensile stress on the duration of the load action 1. quartz glass (damp); 2. Porcelain (dry); 3. Sodium-calcium silicate glass (damp).

Table 1. Strength of ceramic crystalline materials on compression or bending-MPa load velocity $0.13 \mathrm{~mm} / \mathrm{min}$. In different gaseous environments and at different temperatures.

\begin{tabular}{|c|c|c|c|c|}
\hline \multirow{3}{*}{ Material } & \multicolumn{4}{|c|}{ Trial conditions } \\
\hline & \multirow{2}{*}{$\begin{array}{l}\text { Liquid nitrogen, } \\
-195^{\circ} \mathrm{C}\end{array}$} & \multirow{2}{*}{$\frac{\mathrm{Dr}}{\text { y nitrogen } 240^{\circ} \mathrm{C}}$} & \multicolumn{2}{|c|}{ Water-saturated steam } \\
\hline & & & $240^{\circ} \mathrm{C}$ & $25^{\circ} \mathrm{C}$ \\
\hline Quartz glass (compression) & 4600 & 4530 & 2570 & 3910 \\
\hline Granite (compression) & 2620 & 1380 & 420 & 1640 \\
\hline Spodumen (Compression) & 6680 & 4020 & 3200 & 2710 \\
\hline Quartz (compression) & 5720 & 4480 & 2510 & 3670 \\
\hline MgO-Crystal (bending) & 2140 & 1870 & 560 & 1000 \\
\hline $\mathrm{Al}_{2} \mathrm{O}_{3}$ Crystal (bending) & 10,700 & 8200 & 4800 & 7730 \\
\hline
\end{tabular}


hardness of porous ceramics is reduced and by increasing porosity it changes approximately exponentially $[8]^{1}$. We have already proposed the dependence of the macromechanical characteristics on the porous phase [9]. Very significant in it are the dimensions, shape, and defects of Winkelmann and Shock crystals, such as various types of dislocations and others.In materials such as aluminum and beryllium oxides decomposition can be observed along grain boundaries (Picture 2 and Picture 3).

Experiments have shown that fine-grained specimens are more durable than large-grained specimens [10] [11] [12] [13], since the length of Griffiths microcracks is determined by the size of the grains (Picture 4). Presumably this phenomenon is related to the formation of tensions at the grain boundaries as a result of anisotropic thermal expansion. a1900 degree As a result of burning of aluminum oxide ceramics at $1900^{\circ} \mathrm{C}$ temperature grains of several millimeters in sizecan be produced.Under these conditions, quite large tensions are revealed at

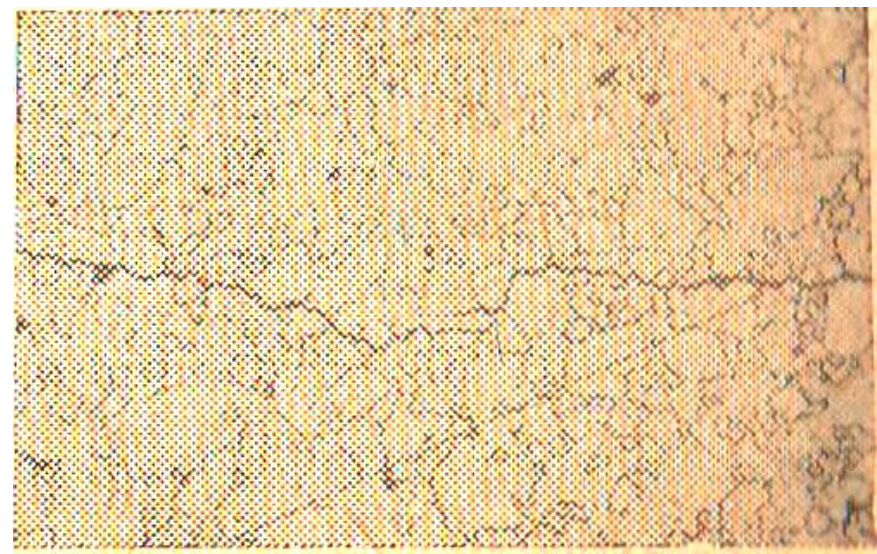

Picture 2. Crack propagation under the influence of thermal shock of aluminum oxide polycrystalline ceramics $150 \times$ according to Coble R. L.

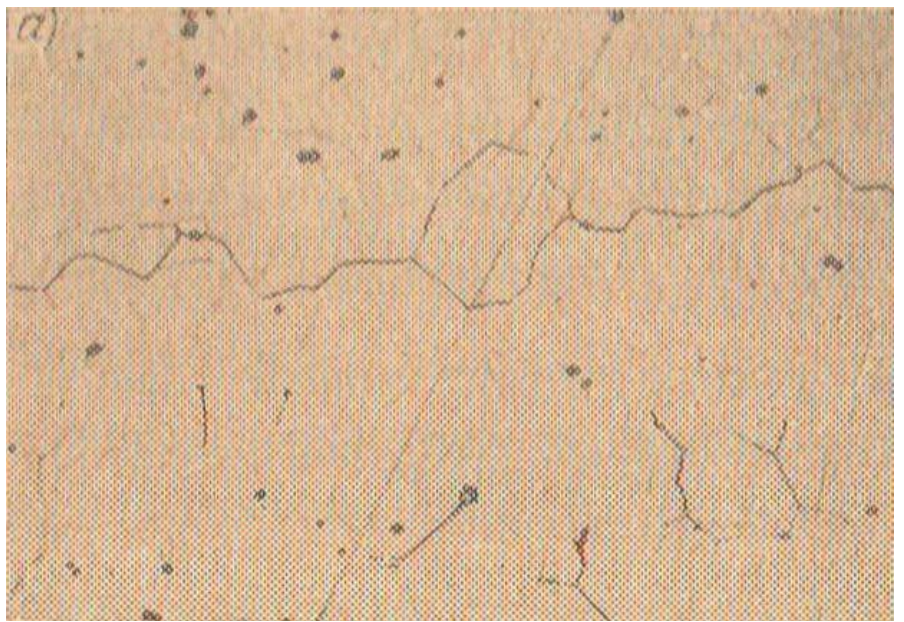

Picture 3. Disintegration of grains along the grain, in large-grained dense aluminum oxide ceramics-anshlif 150x.

\footnotetext{
${ }^{1}$ exponent from Latin: exponentis, which means show. Exponential function is the same as representative function $\mathrm{y}=\operatorname{expx}$.
} 
the grain boundaries, which can lead to such a large self-cracking of the ceramics that individual grains can be ejected with the tip of a knife.If we assume that half the length of the most dangerous crack for the material will be equal to the grain diameter, then, as it follows from the equation [2], the magnitude of the decomposing stress must be inversely proportional to the square root from the grain size. In multi-layered systems different factors can play a key role in relation to the decomposition types.

In general, the dependence of strength on the formation of stresses on the boundaries of phases is relatively characteristic, which is due to their different thermal expansion coefficients, which can cause formation of internal cracks, which are common in the presence of quartz grains in porcelain [14] (Pictures 5-8).

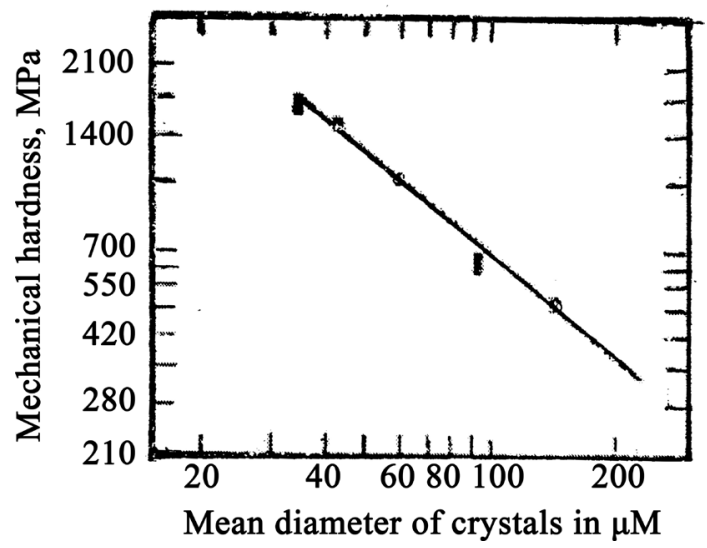

Picture 4. Polycrystalline baked ceramics Dependence of beryllium oxide strength on grain size Mechanical hardness MPa and mean diameter of crystals in $\mu \mathrm{M}$.

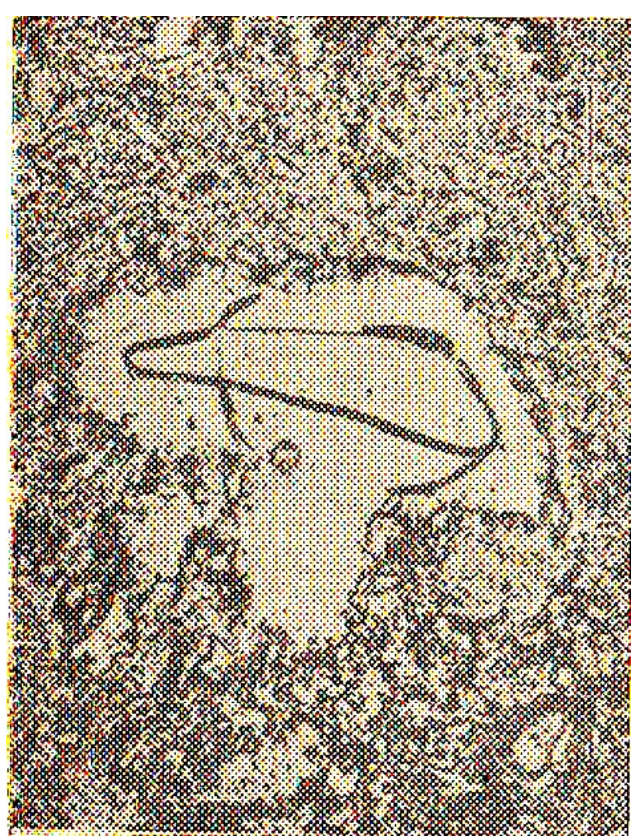

Picture 5. Partially soluted quartz grains in electrical insulation porcelain (poisoning 10 sec, at $0^{\circ} \mathrm{C} 40 \% \mathrm{HF}-\mathrm{Si}$. aluminum replica, $2750 \times$ according to Landin). 


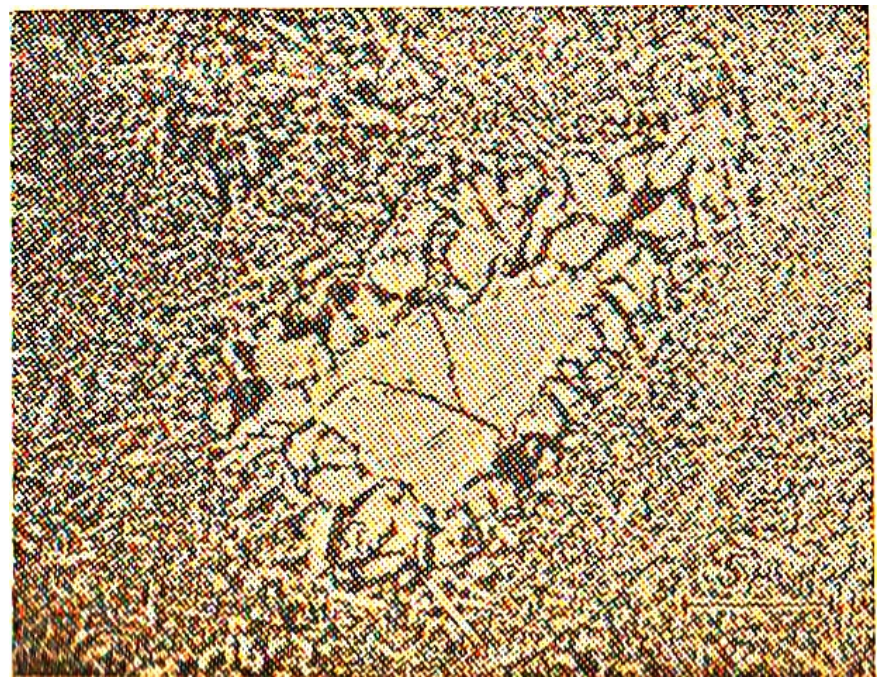

Picture 6. Quartz grain created on the surface with Christobalite inserts (poisoning 20 min, at $100^{\circ} \mathrm{C}$ in $50 \%-\mathrm{NaOH}$. Quartzreplica, 3650×), according to Landin

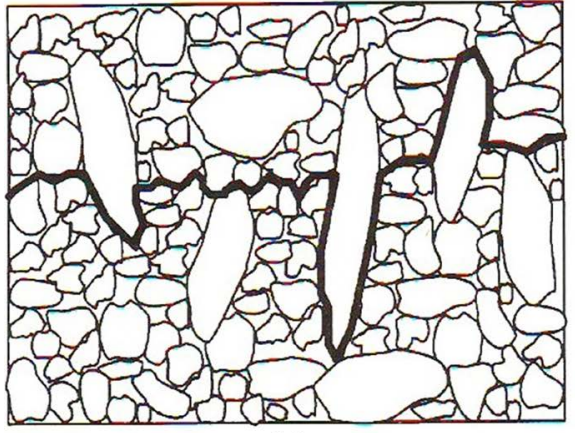

(a)

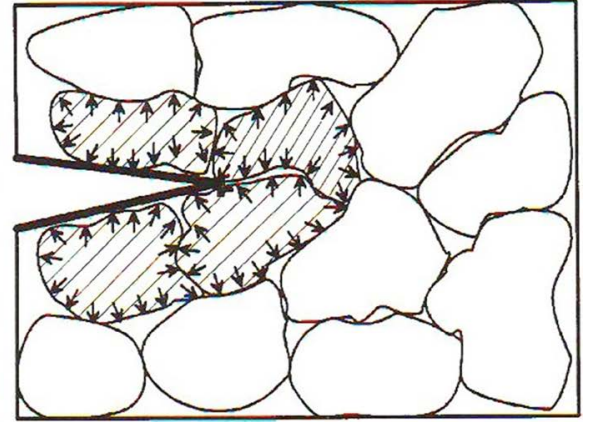

(b)

Picture 7.Mechanisms of crack resistance in ceramics. (a) Crack bridge in $\mathrm{Si}_{3} \mathrm{~N}_{4}$ in ceramics; (b) Transforming reinforcement in $\mathrm{ZrO}_{2}$ ceramics.
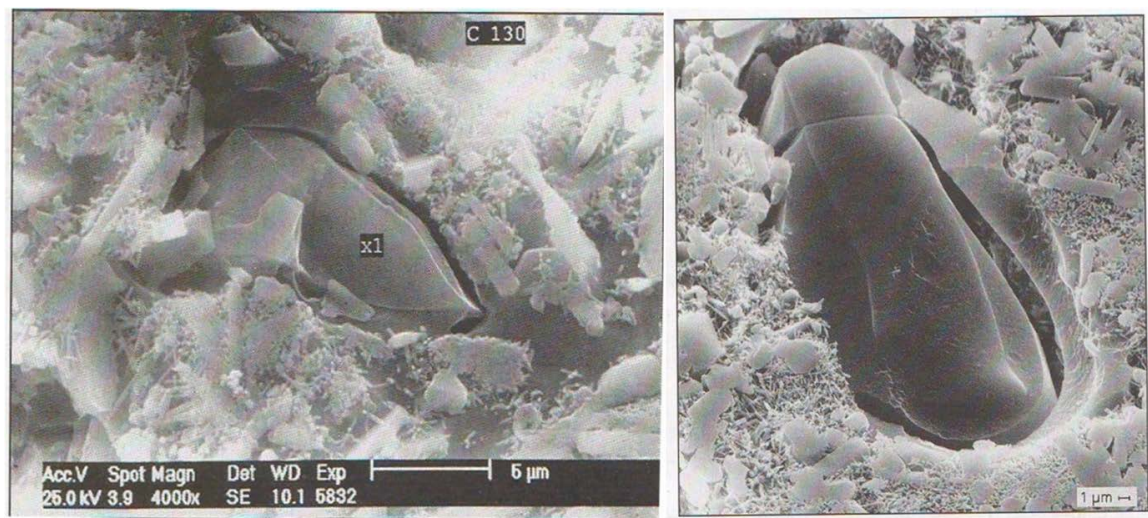

Picture 8. Cracked quartz grains with tension crack in porcelain containing aluminum oxide.

We must promptly consider the second plastic phase as a means of stopping the growth of cracks that have arisen in the fragile phase. This applies, for example, to cermets such as tungsten carbide-cobalt and titanium carbide-nickel. They have 
high strength and durability, but their disintegration is fragile. Observations have shown that cracks are formed in the carbide crystals but stop at the phase boundary. This has been confirmed in our studies (Picture 9).

Thermal stability

If the ceramic material undergoes sharp temperature changes-thermal shocks, then they develop significant stresses, which damage not only the matrix, but

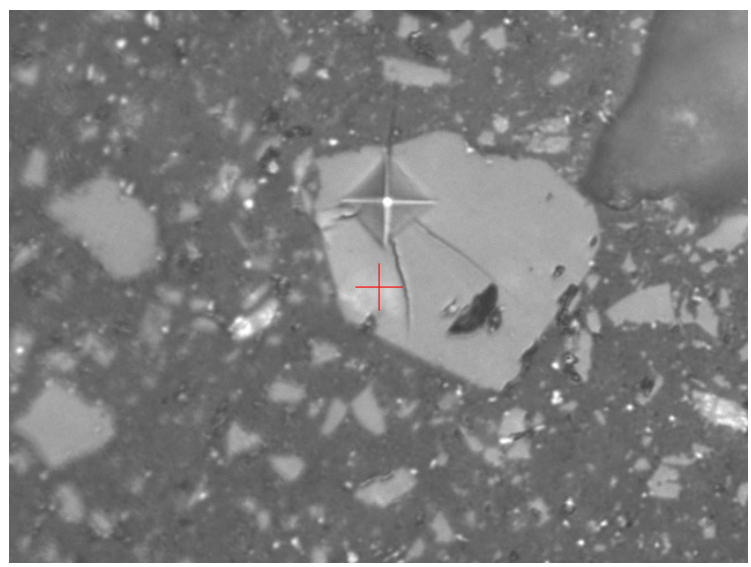

(a)

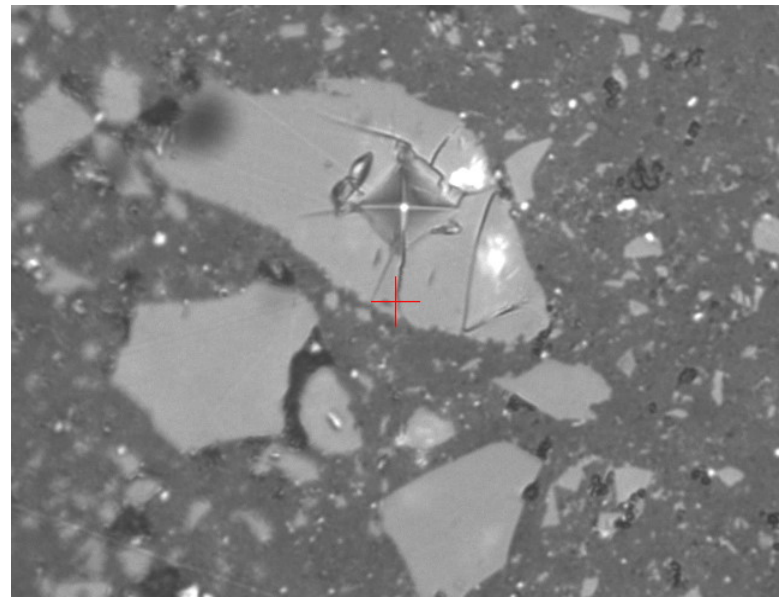

(b)

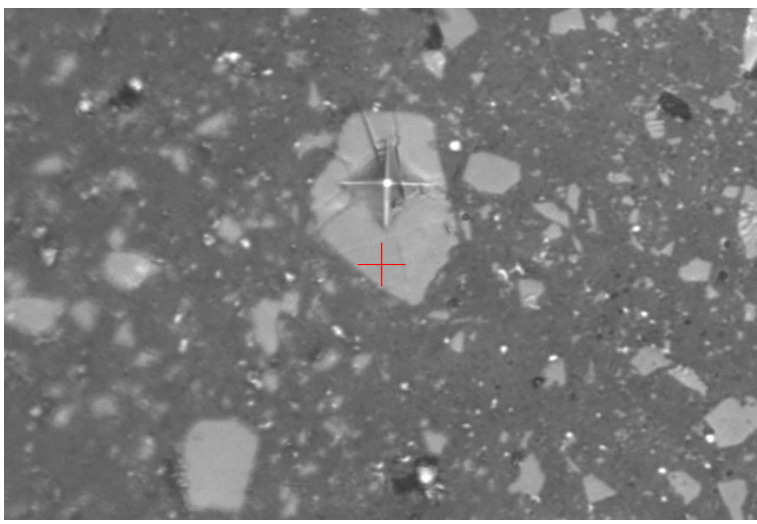

(c)

Picture 9. Cimprints are taken on a silicon carbide grain. 
also the main reinforcing component-the crystalline phase. The higher the strength limit, the higher the thermal resistance is, the lower the elastic modulus and the thermal expansion coefficient.It should be noted here that such a ratio is acceptable when the surface cools down so rapidly that its temperature reaches its final value before the average temperature of the sample changes. This condition is quite good if the bio criterion $\beta=r_{m} h / k$ is 20 or more than 20 . Here $r_{m}$-half the thickness of the workpiece; $h$-heat transfer coefficient; $k$-thermal conductivity.

In general, if we use the second coefficient of thermal stability $R^{1}=k \sigma_{\text {hardness }}(1-\mu) E a$, where $\sigma_{\text {hardness }}$-mechanical strength on bending; $\mu-$ Poisson's ratio; $E$-elasticity modulus; $a$-thermal expansion coefficient.

$$
\Delta T_{\text {decomp. }}=R^{1} S / 0.31 r_{m} h
$$

$R^{1}$ which is determined by the properties of the material, also takes into account its thermal conductivity, and the maximum temperature change that a sample can withstand without disintegration is inversely proportional to its size. Thus, the situation here is very difficult and requires a more accurate analysis of the conditions under which the material is tested or a detailed study of the operational properties of this finished product.As shown above, the operational properties of any ceramic material and composites are significantly determined by the properties of the main component, the crystalline phase, in it.

It should also be noted that other phases in the material, such as glass and porous phases, to some extent determine the operational properties of the product.The dimensions of the crystalline compound, their lattice structure, shape, distribution factor in the matrix, the defects in it significantly determine the operational properties of the product.Based on the above, we considered it necessary to offer a formula for the correlational dependence of the influence of the crystalline phase 1 [15] on the mechanical properties of materials:

$$
\sigma_{d}=\frac{P \cdot F_{k d}}{K_{m} K_{v} F_{k f}}
$$

where: $P$-is loading $\mathrm{MPa} ; K_{m}$-mean size of the crystals $\mu \mathrm{M} ; K_{V}$-volumetric share of crystals in the matrix \%; $F_{k d}$-factor of distribution of crystals in the matrixis defined by a researcher. In case of equal distribution $=1$, in case of unequal distribution $=0.9 F_{k f}-$ shape factor of the crystals is taken as the ratio of the largest characteristic size of the crystal to the smallest, which allows us to characterize the shape of a given combination of crystals. Table 2 shows the data of the crystalline phase of the silane composite obtained by us by metallo-thermic and nitrogenation processes and then synthesized by hot pressing at $1620^{\circ} \mathrm{C}$, [16], according to which we can calculate the correlation of the mechanical characteristic with the characteristics of the crystalline phase with the formula proposed by us.

$$
\sigma_{d}=\frac{470 \times 1}{5 \times 90.6 \times 5}=\frac{470}{2265}=0.21
$$


Table 2. $\mathrm{SiC}, \mathrm{Al}_{2} \mathrm{O}_{3}$ and $\mathrm{SiAlON}$ grain sizes and contents in the matrix.

\begin{tabular}{|c|c|c|c|c|c|c|c|}
\hline $\begin{array}{c}\text { Print } \\
\text { Picture No. }\end{array}$ & $\begin{array}{l}\text { Phase } \\
\text { name }\end{array}$ & $\begin{array}{l}\text { Sight area } \\
\qquad \mathrm{S}, \mu \mathrm{M}^{\mathrm{a}}\end{array}$ & $\begin{array}{l}\text { Number of } \\
\text { grains } \\
\text { counted, } \mathrm{n}\end{array}$ & $\begin{array}{c}\text { The greatest } \\
\text { Grain Dmax. } \\
\mu \mathrm{M}\end{array}$ & $\begin{array}{c}\text { The smallest } \\
\text { Grain Dmin. } \\
\mu \mathrm{M}\end{array}$ & $\begin{array}{c}\text { Grains } \\
\text { Dmid. } \\
\mu \mathrm{M}\end{array}$ & $\begin{array}{c}\text { Phase } \\
\text { content } \%\end{array}$ \\
\hline 17 & $\mathrm{SiC}$ & 1740 & 85 & 33.3 & 2.70 & 4.80 & 26.8 \\
\hline 13 & $\mathrm{SiC}$ & 3225 & 300 & 23.0 & 2.75 & 4.90 & 27.6 \\
\hline Average & & & & & & 4.85 & 27.2 \\
\hline 5 & SIALON & 35,500 & 250 & 19.6 & 5.50 & 8.60 & 53.0 \\
\hline 32 & SIALON & 8200 & 200 & 24.3 & 5.80 & 7.50 & 59.8 \\
\hline 26 & SIALON & 1400 & 220 & 21.7 & 5.30 & 8.50 & 59.3 \\
\hline Average & & & & & & 8.20 & 57.4 \\
\hline 5 & $\mathrm{Al}_{2} \mathrm{O}_{3}$ & 35,500 & 60 & 2.6 & 1.27 & 1.93 & 6.0 \\
\hline $\begin{array}{l}\text { The overall } \\
\text { average size of } \\
\text { the grains }\end{array}$ & & & & & & 5.00 & \\
\hline
\end{tabular}

${ }^{a}$ (From late Latin correlation-ratio, relations that do not have a sharply defined regularity of change, since it is impossible to accurately consider the influence of several simultaneously changing factors. It is used to determine statistical and probabilistic regularities in physics, chemistry, technology, it is also used in probability theory, cybernetics, etc.

where $470 \mathrm{MPa}$ is mechanic of SiAlON composite on bending. In case of compression:

$$
\sigma_{d}=\frac{1910 \times 1}{5 \times 90.6 \times 5}=\frac{1910}{2265}=0.84
$$

where $1910 \mathrm{MPa}$ is mechanic of the material on compression.

\section{Conclusions}

The formula envisages volume and surface defects of crystals, micro and macrostructural volume and surface morphology of the crystalline phase, their composition in the matrix, their distribution in the matrix and the existing transformations in the process of consolidation of materials as a result of chemical and physico-chemical processes. These properties are determined experimentally. It is important that our formula is applicable to any ceramic materials and ceramic composites such as: metal-ceramic, biceramic, glass-metal-ceramic and others.

Our formula, which shows the dependence of macromechanical or characteristics of the complete decomposition of the materials on the size, shape, distribution, and content of crystals in a matrix, the shape factor of the crystal, takes into account the influence of the most powerful phase of the structural components of the consolidated material on the combination of properties that significantly determine the use and durability of products in industry. In the process of thermal processing extremely important is dynamics of the formation of crystals, their redistribution in the matrix, the formation of the shape, which is shown in our study, taking into account the physico-chemical processes that take place during thermal aggression. Our formula provides a complete answer 
to the correlation between the morphology of the crystalline phase of ceramic products and the macromechanical properties and can be used for all types of ceramic and ceramic composites used in advanced technologies, in many fields of technology, household conditions and etc.

\section{Conflicts of Interest}

The author declares no conflicts of interest regarding the publication of this paper.

\section{References}

[1] Kingeri, U.D. (1967) Introduction in Ceramics. Publisher of Literature in Construction, Moscow, 390-391.

[2] Griffith A.A. (1925) First International Congress for Applied Mechanics (Delft). In: Waltman Delft, J., Ed.

[3] Griffith, A.A. (1920) Philosophical Transactions of the Royal Society of London, A221, 163.

[4] Inglis, C.E. (1913) Trans. Inst. Nav. Archit, 55, 219.

[5] Orowan, E. (1934) Die mechanischen Festigkeitseigenschaften und die Realstruktur der Kristalle. Zeitschrift für Kristallographie-Crystalline Materials, 89, 327. https://doi.org/10.1524/zkri.1934.89.1.327

[6] Charles, R.J. (1958) Static Fatigue of Glass. I. Journal of Applied Physics, 29, 1549. https://doi.org/10.1063/1.1722991

[7] Baker, T.C. and Preston, F.W. (1946) Fatigue of Glass under Static Loads. Journal of Applied Physics, 17, 170. https://doi.org/10.1063/1.1707702

[8] Kovziridze, Z. (2018) Macro-Mechanical Properties-Porous Phase Dependens Formula. Georgian Patent. “Saqpatenti”. Certificate 7276.

[9] Artobolevski, I.I. (1977) Politechnical Dictionary. Publisher "Sovetskaia Enziclopedia", Moscow, 572.

[10] Kovziridze, Z., Aneli, J., Nijaradze, N. and Tabatadze, G. (2017) Ceramic and Polymer Composites. Monograph. Member of Omni Scriptum Publishing Group, Mauritius. Lap LAMBERT Academic Publishing, Germany.

[11] Kovziridze, Z., Nijaradze, N., Tabatadze, G. and Aneli, J. (2016) Ceramic and Polymer Composites. Monograph. Georgian Technical University, Tbilisi.

http://www.gtu.ge

[12] Kovziridze, Z., Nijaradze, N., Tabatadze, G. and Darakhvelidze, N. (2017) Composite Materials with SiAlON and Small Quantity Wolfram. Monograph. Georgian Technical University, Tbilisi. http://www.gtu.ge

[13] Kovziridze, Z., Nijaradze, N. and Tabatadze, G. (2014) High Power Hetero-Modulus Composites. Monograph. Georgian Technical University, Tbilisi. http://www.gtu.ge

[14] Kollenberg, W. (2004) Technische Keramik. Vulkan-Verlag ESSEN. S. 52.

[15] Shvedkov, E.L., et al. (1991) Dictionary of New Ceramic Kiev. Naukova Dumka. 91.

[16] Kovziridze, Z., et al. (2017) Obtaining of SiAlON Composite via Metal-Thermal and Nitrogen Processes in the SiC-Si-Al-Geopolymer System. Journal of Electronics Cooling and Thermal Control, 7, 103-122. http://www.scirp.org/journal/jectc 